\title{
A Dimensão Territorial no Trabalho do Assistente Social na Estratégia Saúde da Família
}

\author{
Francinelly Aparecida Mattoso*
}

\begin{abstract}
Resumo: $\mathrm{O}$ artigo analisa as implicações da dimensão territorial no trabalho do assistente social na Estratégia Saúde da Família, com base em entrevistas feitas com os usuários do Serviço Social da Unidade Básica de Saúde Santa Rita, residentes na Vila Sô Neném, em Juiz de Fora, Minas Gerais. Privilegia o enfoque da inserção do assistente social nas equipes de Saúde da Família a partir de seu papel de potencializador de ações e serviços para a população, tendo como elemento constitutivo de seu exercício profissional a dimensão territorial.

Palavras-chave: Trabalho do assistente social; Estratégia Saúde da Família; questão social; território.
\end{abstract}

\begin{abstract}
This article aims to analyse the practice of social workers focusing the territorial implications on the social aspects in dealing with the Family Healthcare Strategy. The paper is based on interviews with the population attended by the Social Service of the "Unidade Basica de Saude de Santa Rita", a community called "Vila Sô Nenem", Juiz de Fora, Minas Gerais. It points out an strategic role for social workers so in promoting actions and services concerned with territorial belonging that help to create new attitude and commitment with public health.

Keywords: Social work labour; Healthcare Family Strategy; territory.
\end{abstract}

\section{Introdução}

A proposta de investigação desenvolvida ${ }^{1}$ versa sobre as implicações das categorias questão social e território no trabalho do assistente social na Estratégia Saúde da Família. ${ }^{1}$ Com vistas a atingir os objetivos propostos para o estudo, foi realizada uma pesquisa qualitativa junto às famílias residentes na "Vila Sô Neném"

\footnotetext{
* Assistente Social. Especialista em Saúde da Família, mestranda em Serviço Social na Universidade Federal de Juiz de Fora. Professora substituta na Universidade Federal de Juiz de Fora. Endereço postal: Rua José Lourenço Kelmer, s/n, Campus Universitário, Bairro São Pedro, Juiz de Fora, Minas Gerais, CEP: 36036.330. Endereço eletrônico: francimattoso@ig.com.br.

${ }^{1}$ A nomenclatura Estratégia Saúde da Família passou a ser utilizada mais recentemente para substituir a denominação Programa Saúde da Família (PSF) devido ao entendimento de que a definição de programa remete a limitações temporais e a amplitude limitada. O PSF transcendeu a definição de um programa setorial de saúde e, dessa forma, o termo estratégia amplia a perspectiva, remetendo a um modelo de atenção em saúde.
} 
acompanhadas pelo Serviço Social da Unidade Básica de Saúde do bairro Santa Rita, em Juiz de Fora (MG).

A "Vila Sô Neném" pode ser caracterizada como uma localidade de risco em virtude das diferentes expressões da questão social que apresenta e consequentemente de seu perfil socioeconômico e epidemiológico. Nesse sentido, buscou-se uma abordagem teórica que permitisse uma discussão e análise dos processos que concorrem para a configuração das especificidades dessa localidade a partir de categorias abrangentes, como a questão social e o território.

Com vistas a problematizar as possibilidades do trabalho do assistente social nesse campo específico de atuação, são desenvolvidas reflexões acerca da Estratégia Saúde da Família no quadro do sistema público de saúde nacional e local e discussões e análises em torno da dimensão territorial, buscando-se para isso caracterizar a "Vila Sô Neném" no contexto da cidade. Paralelamente, são apresentados elementos em torno do trabalho do assistente social na Estratégia Saúde da Família, por meio do enfoque da categoria questão social e das implicações da dimensão territorial para o exercício profissional.

\section{A Política de Saúde no Brasil e a Estratégia Saúde da Família}

Como se sabe, no Brasil o direito à saúde foi assegurado a partir do movimento de diferentes setores da sociedade comprometidos com o projeto de saúde que desembocou no Movimento de Reforma Sanitária no início dos anos 1980. O marco desse movimento se deu em 1986, com a VIII Conferência Nacional de Saúde, a partir da qual foram formuladas as bases para um sistema de saúde brasileiro e várias concepções, ações e práticas foram revistas, redefinindo a própria conceituação de saúde.

É de conhecimento amplo também que, por meio desse processo, foram estabelecidos os mecanismos necessários para que, com a Constituição Federal de 1988, a saúde fosse legitimada como "direito de todos e dever do Estado" e que dessa forma, fossem estabelecidos todos os mecanismos necessários para a efetivação desse direito, com a criação de um sistema único, universal e igualitário, o Sistema Único de Saúde (SUS). O avanço político dessa perspectiva em nossa ordem social e jurídica é tamanha que vale lembrar os termos do que foi instituído:

A saúde é um direito de todos e dever do Estado, garantido mediante políticas sociais e econômicas que visem à redução do risco de doença e de outros agravos e ao acesso universal e igualitário às ações e serviços para sua promoção, proteção e recuperação (BRASIL, 1988, artigo 196).

Dessa forma, vimos a Constituição Federal estabelecer o direito à saúde como um direito fundamental, intrínseco à própria sobrevivência, garantindo legalmente os parâmetros para que esse direito se faça valer. De fato, é justo lembrar que, a partir das garantias legais, com a regulamentação do SUS pelas Leis Orgânicas da Saúde (Leis 8.080/90 e 8.142/90), a saúde, no campo das políticas sociais, se apresenta-se como a área que mais sofreu transformações significativas. As mudanças 
mais expressivas dizem respeito ao reconhecimento da saúde como direito de cidadania e dever do Estado, a alteração do conceito de saúde do campo biológico para o campo político e histórico da construção dos direitos, a descentralização das ações para as esferas estadual e municipal e a democratização do poder por meio dos Conselhos e Conferências de Saúde.

Esse campo normativo estabeleceu que a efetividade do SUS depende da ação conjunta do Estado e da sociedade civil, sendo que para isso deve ocorrer um processo continuado que vise ao seu desenvolvimento e fortalecimento, possuindo como atores centrais na sua condução os sujeitos sociais que são protagonistas nesse cenário, sobretudo os profissionais de saúde e os usuários que fazem uso do sistema por terem esse direito garantido em lei.

Sumariando, as ações e serviços públicos de saúde que integram o SUS são desenvolvidos de acordo com as diretrizes previstas no artigo 198 da Constituição Federal: descentralização, com direção única em cada esfera de governo, atendimento integral, com prioridade para as atividades preventivas, sem prejuízo dos serviços assistenciais e participação da comunidade. Resumidamente, como se sabe o SUS está organizado em quatro níveis de atendimento, de acordo com o grau de complexidade da assistência. Recolocar esses elementos fundantes do sistema se tornaram importantes nessa exposição para bem pontuar aos leitores o quadro institucional em que concebemos o sentido social da assistência analisada aqui. Nesse estudo, estamos interessados no nível primário de atenção, que possui hoje como principal meio de expansão e qualificação a Estratégia Saúde da Família.

A Atenção Primária à Saúde (APS) tem sido reconhecida como espaço táticooperacional de reorientação de sistemas de serviços de saúde mediante a implantação de distritos sanitários e como oportunidade de experimentação de modelos assistenciais alternativos à vertente hospitalocêntrica em consonância com as necessidades de saúde e com o perfil epidemiológico da população. A expressão APS dá lugar à Atenção Básica de Saúde (ABS), para evitar uma concepção de assistência simplificada e de baixo custo.

No que diz respeito à organização do SUS, a $\mathrm{ABS}$ tem sido entendida como o primeiro nível de atenção e como estratégia de reorientação do sistema de saúde, significando que a gestão da atenção básica, ao mesmo tempo em que administra esse primeiro nível de serviços de saúde, deve conduzir a estratégia de reorientação de todo o sistema, buscando uma ação intersetorial.

No ano de 1994, tendo em vista as dificuldades de efetivação do SUS e com o propósito de superação de um modelo de assistência à saúde ineficiente numa conjuntura político-econômica desfavorável à saúde pública em razão da proeminência da ideologia neoliberal, o Ministério da Saúde concebeu o Programa Saúde da Família (PSF). Em linhas gerais, visava a reorganizar os serviços de saúde e facilitar o processo de regionalização e coordenação da integralidade na assistência.

A expansão e a qualificação da atenção básica, organizada pela Estratégia Saúde da Família, compõem parte do conjunto de prioridades políticas apresentadas pelo Ministério da Saúde e aprovadas pelo Conselho Nacional de Saúde no momento de implantação desse modelo. Esssa concepção supera a antiga proposição de caráter exclusivamente centrado na doença, desenvolvendo-se por meio de práticas geren- 
ciais e sanitárias, democráticas e participativas, sob a forma de trabalho em equipes, dirigidas às populações de territórios delimitados, pelos quais essas equipes assumem responsabilidade.

O PSF deve ser entendido como parte de um processo histórico que tem como herança as experiências da Medicina Comunitária no Brasil nas décadas de 1970 e 1980, a qual já demonstrava preocupações com as práticas coletivas, como também o forte apelo desencadeado pela Conferência Internacional sobre os Cuidados Primários em Saúde em Alma-Ata, em 1978, e pelo Movimento pela Reforma Sanitária no Brasil na década de 1980.

Segundo Ronzani e Stralen (2003), na década de 1990, os estudos no Brasil passam a enfocar a família e a comunidade no processo de reorganização dos serviços de saúde. Essa tendência é inspirada no modelo de atenção primária cubano, além de experiências de outros países, como Canadá, Suécia e Inglaterra. Assim, conforme os autores, em 1991 o Ministério da Saúde lançou o Programa de Agentes Comunitários de Saúde (PACS), que teve como experiências iniciais ações realizadas nos estados do Mato Grosso do Sul, Paraná e Ceará, com o objetivo de contribuir para o enfrentamento dos alarmantes indicadores de morbimortalidade infantil e materna.

Posteriormente, com o PSF, objetivou-se reorganizar a prática assistencial em novas bases e critérios, com a atenção centrada na família, entendida e percebida a partir do seu ambiente físico e social, de modo que as equipes de Saúde da Família atuassem referenciadas por uma compreensão ampliada do processo saúde/ doença e de diferenciadas possibilidades de intervenções:

Entender a Saúde da Família como estratégia de mudança significa repensar práticas, valores e conhecimentos de todas as pessoas envolvidas no processo de produção social da saúde. Amplia-se a complexidade das ações a serem desenvolvidas pelos profissionais de saúde e aumentam os limites e suas possibilidades de atuação, requerendo desses profissionais novas habilidades. Além das atividades de assistência desenvolvidas pela ESF, igualmente importantes são as de planejamento como: identificar, conhecer e analisar a realidade local, e propor ações capazes de nela interferir (BRASIL, 2000, p. 73).

Segundo o Ministério da Saúde, entre os princípios sob os quais as equipes de Saúde da Família devem atuar destacam-se: 1) caráter substitutivo - com a substituição de práticas convencionais de assistência por um novo processo de trabalho, com eixo centrado na vigilância à saúde; 2) integralidade e hierarquização - a unidade de Saúde da Família deve estar vinculada à rede de serviços de forma que se garanta atenção integral aos indivíduos e famílias e sejam asseguradas a referência e contra-referência para os diversos níveis do sistema; 3) territorialização e adscrição de clientela - trabalha com território de abrangência definido e é responsável pelo cadastramento e acompanhamento da população adscrita a essa área; 4) equipe multiprofissional - a equipe de Saúde da Família é composta minimamente por um 
médico de família, um enfermeiro, um auxiliar de enfermagem e seis Agentes Comunitários de Saúde (ACS). ${ }^{3}$ Estas equipes são responsáveis pelo acompanhamento de um número definido de famílias, localizadas em uma área geográfica delimitada. Ainda que o território já fosse uma dimensão considerada na saúde pública, em especial na epidemiologia e vigilância sanitária, com o PSF ele ganha contornos mais fundantes e expansivos nas práticas de assistência à saúde.

As equipes têm suas funções normatizadas pelo Ministério da Saúde e atuam com ações de promoção da saúde, prevenção, recuperação, reabilitação de doenças e agravos mais frequentes e na manutenção da saúde não de indivíduos isolados, apenas, mas da comunidade - o que faz com que o terrritório tenha proeminência na assistência.

Do ponto de vista operacional, cada equipe se responsabiliza pelo acompanhamento de até quatro mil pessoas ou mil famílias de uma determinada área. A atuação das equipes ocorre principalmente nas Unidades Básicas de Saúde (UBSs), por meio de ações programáticas e outros tipos de atendimentos nas residências, por meio das visitas domiciliares e na mobilização da comunidade.

A inserção do Serviço Social no campo da saúde vem se ampliando devido a diferentes questões diretamente relacionadas às respostas que essa profissão pode oferecer às variadas demandas postas pela política de saúde e que se apresentam cotidianamente nos serviços, alterando substancialmente as condições gerais de atenção disponibilizada à população usuária.

Os avanços alcançados com o SUS, embora o sistema ainda não tenha sido operacionalizado na sua plenitude, demandam ao Serviço Social atuação sobre necessidades da população usuária no que se refere à articulação de serviços e ações intersetoriais, concomitantemente à apreensão da importância que a informação sobre direitos sociais, saúde e sociabilidades possui no quadro de desenvolvimento e ampliação da consciência sanitária.

Por outro lado, a realidade dos serviços de saúde, em geral, é palco de variados confrontos entre os direitos dos usuários, as normas e as práticas institucionais, demandando a intervenção profissional do assistente social com vistas a assegurar o cumprimento do direito.

Além disso, na atual conjuntura, dois projetos político-institucionais em disputa destacam-se no cenário institucional da área e apresentam requisições divergentes aos profissionais da saúde, quais sejam: o projeto privatista e o projeto da Reforma Sanitária (BRAVO, 2006). O primeiro projeto, de viés neoliberal, possui como pressuposto a desresponsabilização do Estado perante a saúde, a defesa de um modelo mercantil que resulta na precarização do acesso e da qualidade dos benefícios e serviços públicos e na fragmentação e deficiência do trabalho em saúde, permeado por ações imediatas e esvaziadas de postura crítica. Em contrapartida, o projeto de Reforma Sanitária requisita aos profissionais um trabalho convergente

\footnotetext{
${ }^{3} \mathrm{O}$ modelo desenhado pelo Ministério da Saúde aponta para a multiprofissionalidade das equipes que, quando am-pliadas, contam ainda com um dentista, um auxiliar de consultório dentário e um técnico em higiene dental (e-quipe de Saúde Bucal). O acréscimo desses ou de outros profissionais é definido pelos gestores municipais.
} 
aos princípios do SUS e defende a saúde como direito universal, que deve ser alcançado mediante a existência de políticas públicas de qualidade.

A partir dessas premissas, o trabalho do assistente social pode ser compreendido como a atividade que possui entre as suas funções a mediação nas relações dos usuários com os serviços institucionais e com os outros profissionais, diante de casos concretos apresentados. Além de estabelecer relações entre os recursos disponíveis no local de trabalho com os dispostos na rede de serviços sociais, conforme as demandas presentes.

A inserção profissional do assistente social na saúde pode, então, ser entendida a partir da efetivação de ações voltadas para a promoção e prevenção em saúde, contemplando as determinações sociais do processo de saúde-doença, o que significa potencializar o campo da saúde pela interdisciplinaridade dos diferentes saberes que se apresentam na ação.

O universo de conhecimento social do Serviço Social torna o assistente social profissional estratégico para rever e reconstruir o objeto de intervenção na assistência à saúde. Dadas as condições de vida da população atendida, torna-se agente privilegiado para se ocupar da interligação entre o conhecimento biológico e social. As condições sociais afetam a saúde e é necessário compreender as origens, as respostas e possíveis alternativas frente aos problemas sociossanitários. De maneira geral, esse é um campo de interpretação do processo saúde-doença essencial na herança da reforma sanitária e, por meio da presença do assistente social nas equipes, há chance efetiva de se tornar capilarizada no cotidiano dos serviços de saúde e na Estratégia Saúde da Família, em particular.

\section{A Estratégia Saúde da Família em Juiz de Fora}

\section{e a Inserção do Assistente Social}

Juiz de Fora ${ }^{4}$ possui sua rede municipal de serviços de saúde distribuída em oito regiões administrativas, correspondendo cada região a um território que abrange determinado número de bairros segundo a localização geográfica destes.

Atualmente, as ações básicas de saúde são desenvolvidas por 57 UBSs, sendo 42 na área urbana e quinze na área rural. O acesso ao sistema se dá por meio das UBSs, as quais convivem nos dois modelos de atenção básica: tradicional, cujo atendimento é organizado nas clínicas básicas (clínica médica, pediatria e ginecologia), e o de Saúde da Família, que trabalha com equipes mínimas, contando ainda com profissionais odontólogos e assistentes sociais inseridos nos dois modelos.

Juiz de Fora possui 84 equipes de Saúde da Família distribuídas em 37 Unidades Básicas de Saúde (32 UBSs na área urbana, quatro na área rural e uma volante), com uma cobertura populacional de $55,67 \%$, o que corresponde a aproximadamente 290.000 habitantes (BRASIL, 2009).

\footnotetext{
${ }^{4}$ Juiz de Fora, cidade de porte médio, localizada na mesoregião da Zona da Mata Mineira, no sudeste de Minas Gerais, possui uma área total de $1.429,8 \mathrm{Km}^{2}$ e uma população hoje estimada em aproximadamente 520.000 habitantes. Essa população se distribui em $99 \%$ na zona urbana e 1\% na zona rural, sendo a composição por sexo caracterizada por uma tendência das populações eminentemente urbanas, com contingente feminino (52\%) maior que o masculino (48\%).
} 
A presença dos assistentes sociais em algumas equipes de Saúde da Família no início da implantação do PSF no município deveu-se ao fato da gestão do SUS de Juiz de Fora ter considerado o profissional com perfil adequado para atuar no programa, como também devido à atuação de assistentes sociais na saúde municipal desde a década de 1970, nos chamados Centros Comunitários, os quais foram transformados em UBSs. ${ }^{5} \mathrm{O}$ critério inicial adotado para implantar o PSF em determinada localidade do município foi o risco de adoecer e morrer das populações envolvidas, com dados obtidos por meio do processo de territorialização das UBSs e com base no Mapa da Fome (IPEA) e Mapa da Cólera (Vigilância Epidemiológica/SMS/JF).

Em Juiz de Fora há ainda a presença de catorze assistentes sociais residentes do Programa de Residência em Saúde da Família que atuam nas três UBSs que sediam a residência, exercendo a profissão na modalidade de treinamento em serviço, sob supervisão de profissionais assistentes sociais da rede de atenção básica de saúde do município. Ou seja, a realidade municipal, tendo em vista que o assistente social não faz parte da equipe mínima do PSF, possibilitou a inclusão desses profissionais por meio da residência.

A Residência em Saúde da Família em Juiz de Fora faz parte da atual política do Ministério da Saúde, em parceria com o Ministério da Educação e Cultura (MEC), de apoio a Residências Multiprofissionais em Saúde (RMS), desde 2002, por meio do projeto ReforSUS. ${ }^{6}$ A residência deve estar voltada, basicamente, para a formação de membros que comporão futuras equipes de saúde com um novo perfil profissional e capazes de multiplicar tal experiência.

No município de Juiz de Fora, a Residência em Saúde da Família é desenvolvida em três Unidades Básicas de Saúde, que adotam a Estratégia Saúde da Família (bairros Parque Guarani, Progresso e Santa Rita); possui duração de dois anos, com carga horária semanal de 60 horas e contemplando ainda o Curso de Especialização em Saúde da Família (lato sensu), com caráter multiprofissional, possibilitando aos residentes o título de especialistas na área de Saúde da Família.

Por ser considerada uma das profissões da Saúde, o Serviço Social é expressivamente considerado nos programas de Residência Multiprofissional em Saúde em nível nacional, sendo que, de acordo com dados da Secretaria de Gestão do Trabalho e Educação na Saúde (SGTES), do Ministério da Saúde, em 2006 o total de vagas ofertadas à profissão em nível nacional era de 56, perdendo em números apenas para a Enfermagem (total de 152 vagas) e para a Medicina (66 vagas), essas últimas profissões típicas da área da Saúde e que compõem a equipe mínima do PSF (BRASIL, 2006).

Uma das localidades contempladas pelo programa de Residência em Saúde da Família em Juiz de Fora diretamente ligada ao estudo que aqui se apresenta é a Vila Sô Neném, localizada no bairro Santa Rita.

\footnotetext{
${ }^{5}$ É bom reforçar que o assistente social não compõe a equipe mínima preconizada pelo Ministério da Saúde. ${ }^{6}$ Projeto Reforço à Reorganização do SUS, instituído em 1996 por iniciativa do Ministério da Saúde com financiamento do BID e Banco Mundial, possuindo, entre seus objetivos, a promoção da qualidade da assistência e da equidade e a racionalização do uso dos recursos públicos.
} 


\section{A Dimensão Territorial na Estratégia Saúde da Família e Possíveis Implicações no Trabalho do Assistente Social}

A abordagem sobre o trabalho do assistente social na Estratégia Saúde da Família se insere no debate sobre a questão social no quadro sociopolítico da sociedade brasileira e a implementação de políticas sociais como uma das respostas à sua emergência. Nesse sentido, identifica-se o Serviço Social como segmento social estratégico, na medida em que se insere no mercado de trabalho como profissão vinculada às formas de enfrentamento das expressões da questão social via políticas sociais. Nesse cenário, destacam-se as políticas públicas estatais, em que os assistentes sociais desempenham originalmente atividades vinculadas à execução terminal dessas políticas e estabelecem contato direto com a população usuária.

Os estudos no meio profissional, ao analisarem a gênese e as determinações históricas e teóricas da questão social, suas expressões na contemporaneidade e sua relação com o Serviço Social, destacam que a questão social é indissociável da sociedade capitalista (IAMAMOTO, 2008). Sua gênese deriva do caráter coletivo da produção contraposto à apropriação privada da própria atividade humana - o trabalho -, das condições necessárias à sua realização, assim como de seus frutos. Observam ainda que a questão social condensa o conjunto das desigualdades e lutas sociais; suas configurações integram tanto determinantes históricos objetivos que condicionam a vida dos indivíduos sociais, quanto dimensões subjetivas, fruto da ação dos sujeitos na construção da história. A questão social expressa, dessa forma, "uma arena de lutas políticas e culturais na disputa entre projetos societários, informados por distintos interesses de classe na condução das políticas econômicas e sociais, que trazem o selo das particularidades históricas nacionais" (IAMAMOTO, 2008, p. 156). A autora, ao tecer considerações sobre a questão social no Brasil contemporâneo, observa que a crise capitalista vivenciada na década de 1970 do século XX, imprimiu profundas alterações nas formas de produção e de gestão do trabalho perante as exigências do mercado mundial sob o comando do capital financeiro, que vêm alterando profundamente as relações entre o Estado e a sociedade. Esse quadro desencadeou novas mediações históricas que reconfiguraram a questão social na cena brasileira contemporânea no contexto da mundialização do capital.

A lógica econômica imposta preza o favorecimento dos investimentos especulativos em detrimento da produção, com a exigência de reduzir custos e ampliar as taxas de lucratividade, o que se encontra na raiz da redução dos níveis de emprego, do agravamento da questão social e da regressão das políticas sociais públicas.

Paralelamente, ocorrem radicais mudanças nas relações Estado/sociedade por meio de vigorosa intervenção estatal a serviço dos interesses privados articulados no bloco do poder, sob inspiração liberal. O Estado reduz então sua ação e os gastos sociais no atendimento às necessidades das grandes maiorias, em nome da chamada crise fiscal do Estado:

Nesse cenário, a "velha questão social" metamorfoseia-se, assumindo novas roupagens. Ela evidencia hoje a imensa fratura entre o desenvolvimento das forças produtivas do trabalho social 


$$
\begin{aligned}
& \text { e as relações sociais que o impulsionam (IAMAMOTO, 2008, } \\
& \text { p. 144). }
\end{aligned}
$$

Na contemporaneidade, a questão social se re-produz sob novas mediações históricas ao mesmo tempo em que assume inéditas expressões ao alterar as bases em que ocorre a produção e a reprodução das desigualdades em um contexto de internacionalização econômica, sob o comando do capital financeiro. lamamoto (2008) destaca que decifrar as novas mediações por meio das quais se expressa hoje a questão social é de fundamental importância para a profissão, tanto para que as várias expressões que assumem na atualidade as desigualdades sociais sejam apreendidas, quanto para projetar e forjar formas de resistência e de defesa da vida. A questão social se constitui assim no campo de atuação profissional.

Mas os estudos também apontam que a questão social na contemporaneidade passa a ser objeto de um explícito "processo de criminalização"7 que atinge as classes subalternas, reciclando a noção de "classes perigosas", sujeitas à repressão e extinção. A tendência a naturalizar a questão social é acompanhada da transformação de suas manifestações em objeto de programas assistenciais focalizados de "combate à pobreza" ou em expressões sobre a violência dos pobres, cuja resposta são a segurança e a repressão oficiais. Dessa forma, evoca-se o passado, quando a questão social era tratada como caso de polícia, ao invés de ser objeto de ação sistemática do Estado no atendimento das necessidades dos trabalhadores.

Portanto, observa-se nos indicadores sociais e estudos analíticos do tema aumento significativo das desigualdades sociais como resultado dos novos processos produtivos e da retração das políticas distributivas, passando a gerar processos de exclusão social via disparidades entre indivíduos e regiões dentro do espaço urbano.

A pobreza inerente ao conflito das classes sociais de onde emerge a questão social precisa ser tomada como um fato da vida urbano-industrial, pois além da maioria dos pobres viver nas cidades e zonas metropolitanas, observa-se que a reprodução da pobreza é mediada pela reprodução do modo urbano das condições de vida, por meio da dinâmica do mercado de trabalho e da natureza do sistema de proteção social (LAVINAS, 2002).

A partir de tais constatações, pode-se afirmar que a questão social inscrevese em permanentes e renovadas novas condições históricas, fruto do aprofundamento das contradições sociais e da ampliação das desigualdades distribuídas territorialmente em que interferem tanto ações do mercado quanto do Estado, ligando a produção e a reprodução social.

Nesse sentido, a questão social destaca-se como elemento decisivo na relação entre trabalho do assistente social e realidade, sendo o conhecimento de suas expressões particulares indissociáveis de uma perspectiva de exercício profissional que possua a dimensão territorial como elemento estratégico na consecução de ações.

\footnotetext{
${ }_{7}$ Netto (2006) observa que uma das características mais marcantes do capitalismo contemporâneo é a "exponenciação da questão social", que continua sendo naturalizada, mas acrescida da "criminalização do pauperismo e dos pobres", com repressão expandida.
} 
Por isso, a partir dessas referências analíticas a seguir, são apresentados elementos sobre a dimensão territorial da questão social que possibilitam pensar possibilidades para o trabalho do assistente social na Estratégia Saúde da Família, na experiência examinada na pesquisa.

A Vila Sô Neném situada no bairro Santa Rita, na parte alta da região leste de Juiz de Fora, é caracterizada como área de risco social devido à presença de fatores de vulnerabilidade à saúde, barreiras geográficas e culturais e indicadores de saúde abaixo dos padrões de referência. Destaca-se, sobretudo, o alto índice de desemprego presente na localidade, o que consequentemente gera problemas ligados à violência, drogadição e extrema pobreza.

A partir do processo de territorialização realizado no bairro Santa Rita, que possui uma população em torno de 5.100 habitantes, a Vila Sô Neném, localidade que possui 550 habitantes distribuídos em 150 domicílios, passou a constituir três microáreas pertencentes à área de atuação de uma das equipes de saúde da família da UBS Santa Rita (cada área é subdividida em até seis microáreas, sendo cada microárea de responsabilidade de um agente comunitário de saúde).

De acordo com Barros e Oliveira (2006), as origens da Vila Sô Neném datam de aproximadamente vinte anos atrás, por meio de um processo de contínuas ocupações irregulares de lotes que pertenciam a uma família que teve como protagonista um morador antigo do bairro (o Sô Neném), que passou a construir casas de aluguel nessa localidade, intensificando o povoamento da região. Para o local, a prefeitura transferiu famílias desabrigadas vítimas de fortes chuvas, como também ocorreu um movimento de posse pacífica, contínua e incontestada de lotes e moradias já construídos por parte de moradores de outras partes da cidade. Esse processo, como também a falta de infraestrutura básica e a precariedade das moradias, passou a particularizar essa porção territorial dentro do bairro, hoje densamente ocupada, conhecida como Vila Sô Neném devido ao nome pelo qual o sujeito principal de sua ocupação era conhecido.

A população da Vila Sô Neném caracteriza-se como trabalhadora empobrecida, sendo alto o percentual de indivíduos em fase produtiva e reprodutiva. No tocante às doenças e agravos identificados na localidade, destacam-se os casos de hipertensão arterial, diabetes, deficiência física, transtornos mentais, dependência química, câncer, desnutrição, anemia falciforme, hanseníase, tuberculose e HIV/ AIDS.

Em relação à ocupação da população residente, destaca-se o grande número de biscateiros, domésticas e diaristas, pedreiros e serventes de pedreiros, auxiliares de serviços gerais, catadores de papel, desempregados e do lar, além dos que se enquadram na categoria de beneficiários do INSS por serem aposentados ou pensionistas e por estarem recebendo auxílio-doença, além do Benefício de Prestação Continuada (BPC). A renda familiar predominante é de até dois salários mínimos, sendo que muitas são as famílias beneficiadas por programas de transferência de renda.

É expressiva a presença das famílias monoparentais (com apenas um dos pais presente, em especial em que a mulher assume sozinha a chefia do domicílio), sendo que muitas vezes há uma nítida fragilização dos vínculos afetivos e de per- 
tencimento social devido às dificuldades de acesso ao mercado de trabalho e aos serviços públicos.

Observa-se ainda que muitas famílias vivem em pobreza persistente, principalmente as monoparentais compostas por mulheres e crianças, que, segundo estudo, são segmentos que têm muito mais dificuldades de escapar da pobreza. Dessa forma, os integrantes das famílias são interdependentes, sendo que essa interdependência acaba sendo estratégia, criada pelos seus membros, objetivando o enfrentamento das adversidades presentes cotidianamente e que acabam rebatendo negativamente no desenvolvimento das crianças, que cada vez mais cedo assumem responsabilidades, e na qualidade de vida dos idosos, que, com suas rendas, asseguram a subsistência dos outros membros da família.

O caráter das atuais transformações socioeconômicas, decorrentes da chamada revolução técnico-científica e do processo de globalização, impõe um permanente olhar sobre o fenômeno urbano no Brasil e suas implicações na reprodução do espaço geográfico, já que novos significados são produzidos em decorrência das transformações em curso. Na esteira dessas reflexões, Santos (1991) sugere pensar o território como pleno de relações de poder e intencionalidades no espaço, como as corporificadas pela intermediação do Estado, das demais instituições e do conjunto de agentes da economia, a começar pelos seus atores hegemônicos. Carlos (1996) observa que o espaço intervém na produção e na organização do trabalho produtivo, ao mesmo tempo em que determina as relações de produção e é também produtor e produto, suporte das relações sociais e, portanto, tem papel importante no processo de reprodução geral da sociedade. A produção espacial aparece nas formas de apropriação, utilização e ocupação de um determinado lugar, num momento específico que se revela no uso, como produto da divisão social e técnica do trabalho. As relações sociais de produção têm uma existência social como existência espacial, isto é, projetam-se concretamente no espaço.

A apreensão territorial dos processos sociais sugere levar em consideração que o território é uma construção decorrente do processo histórico, resultante da ação de homens concretos e em permanente transformação, em que tensionam-se as forças sociais em jogo. Ao mesmo tempo em que é resultado de ações sociais, é condição para que as relações sociais se concretizem, sendo historicamente determinado e pertencente a uma dada coletividade de um dado local, que articula as forças sociais de determinada maneira.

Indissociável da dimensão espacial está a dimensão temporal, tendo em vista que, em um mesmo espaço, podem coexistir diferentes períodos. O espaço, a partir de sua caracterização como um conjunto de elementos no qual coexistem diferentes épocas, sintetiza a trajetória da sociedade e auxilia na explicação das situações presentes na atualidade. Nesse sentido, o território é composto pelas ações passadas e pelas presentes, dando forma ao território hoje existente.

Santos (1993) chama a atenção para o fato de que a rede urbana adquire significados diversos segundo a posição financeira do indivíduo, havendo num extremo aqueles que podem utilizar todos os recursos aí presentes e na outra extremidade aqueles que nem podem levar ao mercado o que produzem, os que, pobres de recursos, são prisioneiros do lugar, isto é, dos preços e das carências locais. 
Para o autor, morar na periferia é condenar-se duas vezes à pobreza. À pobreza gerada pelo modelo econômico, segmentador do mercado de trabalho e das classes sociais, superpõe-se a pobreza gerada pelo modelo territorial. Esse irá determinar quem deve ser mais ou menos pobre somente por morar nesse ou naquele lugar.

Além da distribuição desigual dos recursos no espaço urbano, verifica-se concomitantemente um ritmo de crescimento diferenciado entre os lugares. Dessa forma, são estabelecidas drásticas diferenças de condições de vida nas várias regiões e bairros das cidades. O espaço urbano, assim, reflete uma sociedade desigual e classista, que é também marcada por relações de conflito e poder.

Como resultado desse modelo de desenvolvimento, as cidades brasileiras se organizam de forma segregada: de um lado a consolidação de supostos territórios de modernidade e do outro, territórios de extrema pobreza. O que se manifesta é a convivência, na mesma cidade, de espaços carentes de infraestruturas, equipamentos urbanos e transportes regulares, com ilhas de progresso e modernidade, sendo que a desigual distribuição de recursos determina a existência de zonas de risco social intenso. A divisão territorial passa então a ser uma divisão de classe.

Na cidade, hoje é fácil identificar territórios diferenciados, onde cada qual conhece o seu lugar e se sente estrangeiro nos demais. É um movimento de separação das classes sociais e funções no espaço urbano, caracterizando o que os estudiosos da cidade chamam de segregação espacial. ${ }^{8}$

Nesse processo, cabe salientar o que Cassab (2005) aponta como uma naturalização da violência a partir da identificação de alguns como perigosos a partir de sua posição de classe e da ocupação e uso que fazem do espaço da cidade.

Esses aspectos ficaram explícitos na fala de moradores da Vila Sô Neném a partir das respostas que ofereceram à pergunta "Como você visualiza o local em que você mora em relação aos outros lugares da cidade de Juiz de Fora? Quais são os pontos positivos e negativos de se viver aqui e que mudanças deveriam ocorrer neste lugar?" quando foi realizada a pesquisa de campo para este estudo.

Ao responderem a essa questão, os entrevistados remeteram-se ao bairro como um todo e à Vila Sô Neném especificamente, sendo que, em sua maioria, observaram que o bairro não é um lugar bom para viver, já que há moradores que os entrevistados identificam como perigosos, porque roubam os vizinhos ou ainda cometem delitos dentro e fora do bairro. Dessa forma, afirmaram que outros bairros da cidade são mais tranquilos e melhores para morar.

Essa constatação pode ser exemplificada pelos depoimentos dos entrevistados quando observaram a regularidade com que a polícia vai ao bairro e também a forma como ela implementa suas ações (solicita documentos a todos, a partir de um pressuposto de que todos são suspeitos).

A forma como o bairro é visualizado pela população de outros bairros e por instituições públicas e privadas proporcionam a vivência de discriminações, precon-

${ }^{8}$ Ver HARVEY (2004). Outro termo que remete a compreensão semelhante é exclusão territorial, utilizado por ROLNIK (2002). 
ceitos e falta de oportunidades no mercado de trabalho aos seus moradores. Essa questão fica clara na fala de duas entrevistadas:

Eu vejo um lugar ruim de morar. Todo bairro tem, mas aqui se você tiver na beira de seu passeio e os outros tiver fumando, você toma geral. Às vezes, tá tranquilo e passa os homens pedindo documento" [Referência às ações policiais no bairro]. [...] Uma vez fui procurar serviço e aí a moça perguntou o bairro que eu morava. Tava tudo certinho. Aí ligou para mim e perguntou o bairro em que eu morava. Quando eu falei o bairro, ela desistiu e falou que tinha gente na frente. Por causa da fama do bairro não deu certo (J., em entrevista à autora, 2007).

Aqui é um bairro violento, né. Diariamente você vê na televisão que alguém roubou, matou no Santa Rita. O pessoal fala muito mal daqui. Quando você vai procurar emprego não consegue (P., em entrevista à autora, 2007).

Os entrevistados destacaram que o fato de o bairro possuir a fama de violento e ser um local ruim para viver deriva do comportamento de seus moradores, que são apontados como pessoas de difícil convivência, desagradáveis e não-solidários.

Em relação ao que consideram algo positivo no local em que moram, destacaram a proximidade do bairro com a região do Centro e a atuação da equipe de Saúde da Família pela responsabilização, o vínculo e a proximidade estabelecida com os moradores.

Quanto às melhorias que deveriam ocorrer na localidade, os entrevistados relataram a necessidade de serviços públicos que resolvam os problemas existentes, apontando para a importância de um posto policial no bairro, a necessidade de atendimento odontológico na UBS, uma melhor destinação do lixo e maior fiscalização pelos órgãos competentes no que se refere aos animais soltos pelo bairro.

A redefinição das diretrizes das políticas e das ações das equipes profissionais nas áreas de intervenção supõe o conhecimento do território nas suas medidas intraurbanas, o que possibilita levantar, além das carências, as potencialidades do lugar, para o fomento de estratégias específicas da ação pública, implicando a participação dos sujeitos que constroem essas potencialidades locais.

A intervenção das políticas públicas deve estar atenta às condições individuais de vida das pessoas e às construções de relações acumuladas na coletividade, tendo em vista que o aspecto relacional se faz intrínseco às condições de vida.

A referência ao corpo, ou ao indivíduo, é relevante, na medida em que permite a compreensão de que os indivíduos em questão são sujeitos sociais que vivenciam as contradições e privações comuns a todos aqueles que ocupam determinado lugar social. Nessa perspectiva, surge a possibilidade de um novo entendimento para as demandas sociais apresentadas, a partir da defesa dos direitos de cidadania. Além disso, as ações desenvolvidas a partir dessa compreensão poderão significar uma incidência no território de impactos reais em sua organização espacial e ampliação de acesso aos bens socialmente produzidos. 
Nessa perspectiva, a noção de território implica não somente a discussão física, mas as relações construídas pelos homens que nele vivem, considerando-se a dimensão cultural das populações, suas particularidades, seus anseios e não somente suas necessidades. Paralelamente, tal perspectiva proporciona o fomento da discussão sobre o fato de o território contemplar possibilidades de inclusão social, efetivação da cidadania e democratização de informações, com a consequente participação dos indivíduos na vida da cidade.

Remetendo-se a Milton Santos, Balbim (2003) destaca que é a relação com o lugar que singulariza a abordagem geográfica do cotidiano, a partir da possibilidade do acontecer solidário e da união de uma diversidade enorme de existências. O lugar, assim, pressupõe o futuro como projeto e o passado como herança.

O cotidiano apresenta ainda a possibilidade para a espontaneidade das ações a partir do lugar, a partir do que dele é específico, de suas qualidades e identidades próprias.

A Estratégia Saúde da Família configura-se em um campo fértil para o trabalho do assistente social por possuir uma dimensão comunitária que possibilita a realização de um fazer profissional que contemple novas possibilidades e exigências de atuação a partir das demandas apresentadas pelos usuários no cotidiano.

O assistente social, nesse campo de atuação, depara-se com situações singulares vividas por indivíduos e famílias, grupos e segmentos populacionais, que são atravessadas por determinações da estrutura de classes sociais. O profissional pode apreender, nas situações singulares que atende, as dimensões universais e particulares que aí se concretizam, qualificando o trabalho em saúde na perspectiva pioneira institucionalizada pelo SUS acerca das determinações das condições de vida e suas implicações sobre o processo saúde-doença. Para lamamoto (2008), essa necessidade se impõe como condição de trânsito das necessidades sociais da esfera privada para a luta por direitos na cena pública, o que requer atribuir visibilidade aos fios que integram o singular no coletivo quanto ao conhecimento do modo de vida, de trabalho e expressões culturais desses sujeitos sociais, como requisitos essenciais do desempenho profissional. Tarefa bastante coerente ao assistente social nas equipes de saúde, mesmo que não exclusiva.

Dessa forma, por estar em contato direto e cotidiano com as questões de saúde da população atendida, que compreendem desde demandas específicas relacionadas a cada segmento populacional (gestantes, crianças, adolescentes, idosos) até questões relacionadas aos diferentes tipos de violência e demandas no campo da educação, da habitação, do lazer, entre outros, ao assistente social são apresentadas potencialidades de trabalho que podem ser traduzidas em ações na esfera da concretização de direitos essenciais.

Ao inserir-se nesse espaço sócio-ocupacional com clareza das implicações ético-políticas de seu exercício profissional e por meio de sua intervenção identificar, analisar e avaliar de que forma a população vivencia as problemáticas apresentadas, o assistente social pode constituir um acervo privilegiado de informações desencadeadoras de ações voltadas ao fortalecimento da população usuária dos serviços e à organização comunitária para a defesa dos direitos sociais.

Por ter contato direto com os usuários, por disponibilizar e socializar conhecimentos, o trabalho do assistente social pode, nesse sentido, interferir nos deter- 
minantes das condições de saúde da população. Esse processo, por conseguinte, poderá alimentar ações inovadoras capazes de propiciar o atendimento às efetivas necessidades sociais para além das demandas instituídas.

\section{Considerações Finais}

O trabalho do assistente social no conjunto das ações que organizam o território possui como eixo central a questão social em suas diversas expressões e especificidades, com o desafio de apreender, no âmbito local, as particularidades assumidas pela questão social para que estratégias reais de ação sejam traçadas e resultados concretos sejam alcançados.

Cabe ressaltar que o trabalho profissional do assistente social nos espaços de segregação sofre repercussões diretas pela forma como o poder público controla as ações visando à governabilidade desses espaços, bem como da ação dos diferentes sujeitos individuais e coletivos, tais como associações e movimentos populares. Ou seja, o trabalho do assistente social se diferencia e se especifica nessas localidades devido à dimensão cultural que faz parte da socialização das pessoas que habitam esses territórios, com base em valores e práticas sociais familiares aos seus habitantes e que incidirão no modo como as políticas e ações profissionais se concretizam, imprimindo uma autonomia relativa ao exercício profissional.

As expressões da questão social em áreas segregadas, como a Vila Sô Neném, são caracterizadas pelo aprofundamento de um quadro já demarcado por situações especiais de risco, como a existência de precárias condições de saúde, o envolvimento em atividades ilícitas, a presença de formas variadas de violência, o desemprego e a inserção informal no mercado de trabalho, a baixa escolarização, entre outros. Em tais circunstâncias, as famílias, em sua maioria, não apresentam condições de articular minimamente os cuidados de seus membros e por isso necessitam de atenção diferenciada do Estado.

Nesse quadro, os desafios colocados para o Serviço Social são inúmeros, a começar pela tensão entre projetos sociais distintos que presidem a estruturação e a implementação das políticas sociais públicas. O trabalho do assistente social, no âmbito da produção e da reprodução da vida social, ganha contornos fecundos para o trabalho em saúde na perspectiva da reforma sanitária quando estabelece interlocução entre Serviço Social e dimensão territorial. No âmbito da saúde é evidenciada a potencialidade dessa atuação profissional por ser a questão social determinante no processo saúde-doença da população, e sendo a mesma expressão territorial fruto da desigualdade social que se impõe geopoliticamente.

Para o profissional de Serviço Social a noção de espaço socialmente produzido e a de território, nos termos em que ambos são entendidos nesse estudo, é uma fértil via de conhecimento da particularidade das práticas sociais, pois eles incluem as relações de produção, as formas de reprodução, as de circulação e o exercício efetivo do poder na vida cotidiana e suas negações. A partir desse campo de abordagem, é possível vislumbrar a necessidade de luta pela implementação de políticas públicas transversais, capazes de dar respostas efetivas às diferentes demandas dos territórios.

As respostas profissionais diante desse quadro podem potencializar a articulação dos movimentos coletivos dos segmentos e classes sociais que atribuem 
visibilidade na cena pública ao caráter das necessidades sociais dos indivíduos e grupos, impulsionando a luta por direitos.

A redefinição das diretrizes das políticas e das ações das equipes profissionais nas áreas de intervenção pode fomentar estratégias específicas da ação pública, implicando uma incidência no território de impactos reais em sua organização espacial e ampliação de acesso aos bens socialmente produzidos.

O exercício profissional do assistente social na Estratégia Saúde da Família, assim como dos demais membros da equipe, pode privilegiar a interlocução com outras áreas, buscando a integralidade das ações, a partir da capacidade de promover relações intersetoriais que possam atender demandas relacionadas às condições de vida das pessoas e famílias residentes em um dado território, por meio de políticas públicas mais integradas.

As atividades que o assistente social desenvolve derivam das necessidades sociais dos sujeitos, que, condicionadas pelas lutas sociais e relações de poder, transformam-se em demandas profissionais, o que determina o cotidiano das ações profissionais a partir das condições e relações sociais que circunscrevem esse trabalho. Consequentemente, a atuação profissional do assistente social nesses espaços é permeada por relações conflituosas, o que demarca o caráter político das intervenções profissionais e o papel político-ideológico de seu trabalho. É nesse sentido que a dimensão de espaço socialmente construído e o território vivido incidirão diretamente no trabalho do profissional, já que a configuração destes é indissociável das intencionalidades dos sujeitos na vida social. 


\section{Referências Bibliográficas:}

BALBIM, R. A quinta dimensão do espaço. Cotidiano e práticas espaciais.

SOUZA, M. A. de S. et al. (orgs.). Território brasileiro: usos e abusos. Campinas:

Territorial, 2003, pp. 154-73.

BARROS, D. e OLIVEIRA, D. C. Política urbana em Juiz de Fora: intervenções nas configurações do território com a implementação do planejamento estratégico: o programa JF Bairros na Vila Sô Neném /Bairro Santa Rita. Juiz de Fora: Monografia de Conclusão de Curso de Graduação em Serviço Social. Faculdade de Serviço Social, UFJF, 2006.

BRASIIL. Constituição (1998). Constituição da República Federativa do Brasil.

Brasília, DF: Senado, 1988.

. Guia Prático do PSF. Brasília, DF: Ministério da Saúde, 2000.

- Residência Multiprofissional em Saúde: experiências, avanços e desafios.

Brasília, DF: Ministério da Saúde, 2006.

- Evolução do credenciamento e implantação da estratégia Saúde da

Família. Disponível em http://dtr2004.saude.gov.br/dab historico_cobertura_ sf.php. Acesso em 26 de julho. 2009.

BRAVO, M. I. S. e MATOS, M. C. de. Reforma Sanitária e projeto ético-político do Serviço Social: elementos para o debate. In: BRAVO, M. I. S. et al. (orgs.). Saúde e Serviço Social. 2 ed. São Paulo: Cortez, 2006, pp. 25-47.

CARLOS, A. F. O lugar no/do mundo. São Paulo: Hucitec, 1996.

CASSAB, M. A. T. e CASSAB, C. Jovens e oportunidades: a desnaturalização da cidade desigual. Revista Serviço Social e Sociedade, ano XXVI, n. 83. São Paulo: Cortez, 2005, pp. 49-62.

FRANCO, T e MERHY, E. Programa Saúde da Família (PSF): contradições de um programa destinado à mudança do modelo assistencial. In: MERHY, E. et. al. (orgs.). O trabalho em saúde: olhando e experenciando o SUS no cotidiano. São Paulo: Hucitec, 2004, pp. 55-124.

HARVEY, D. Espaços de esperança. São Paulo: Loyola, 2004.

IAMAMOTO, M. V. Serviço Social em tempo de capital fetiche: capital financeiro, trabalho e questão social. São Paulo: Cortez, 2008.

LAVINAS, L. Pobreza e exclusão: traduções regionais de duas categorias da prática. Econômica, v. 4, n. 1, junho, 2002, pp. 25-59.

NETTO, J. P. e BRAZ, M. Economia política: uma introdução crítica. São Paulo: Cortez, 2006.

ROLNIK, R. É possível uma política urbana contra a exclusão? Revista Serviço Social e Sociedade, ano XXIII, n. 72, São Paulo: Cortez, 2002, pp. 53-61.

RONZANI, T. M. e STRALEN, C. J. V. Dificuldades de implantação do Programa de Saúde da Família como estratégia de reforma do sistema de saúde brasileiro. Revista de Atenção Primária à Saúde, v. 6, n. 2, Juiz de Fora: NATES, UFJF, 2003, pp. 99-107.

SANTOS, M. Metamorfoses do espaço habitado. 2 ed. São Paulo: Hucitec, 1991. . O Espaço do cidadão. 2 ed. São Paulo: Nobel, 1993.

WILKEN, P. R. C. Política de Saúde no Brasil. O Sistema Único de Saúde (SUS): uma realidade em construção. Rio de Janeiro: H. P. Comunicação Editora, 2005.

Recebido em 03 de agosto de 2009.

Aceito para publicação, em 10 de outubro de 2009 